Oncology 1969;23:88

\title{
News
}

\section{WORLD HEALTH ORGANIZATION}

Research Training Fellowships 1970

Applications for training fellowships in 1970 are invited from junior scientists wishing to be trained in any aspect of laboratory and clinical cancer research. The Agency is especially interested in receiving applications for training in epidemiology, biostatistics and all aspects of environmental biology. Applicants should be engaged in research in medical or allied sciences and intend to pursue a career in cancer research. Fellowships are awarded for one year and are tenable in a suitable institution abroad. In special circumstances an extension for a second year may be granted. Fellows will, in general, be selected from applicants with less than five years post doctoral experience in medicine or the natural sciences. They must have an adequate knowledge, both written and spoken, of the language of the country in which their fellowship is tenable. Stipends will vary according to the cost of living in the country of study. The cost of travel for the applicant and, in certain circumstances, that of his wife and children, will be met. Fellowship application forms and more detailed information are available from:

The Chief of the Education and Fellowships Programme, International Agency for Research on Cancer, 16, avenue Marechal-Foch, 69-Lyon (6e), France. Applications must reach the Agency not later than 30 April 1969. 